\title{
AS PRAÇAS DE MAMBORÊ-PR ENQUANTO ÁREAS VERDES URBANAS
}

\section{Ana Claudia Breitkreitz Fernandes Ayres ${ }^{1}$}

\author{
Silvana De Jesus Galdino²
}

Marcos Clair Bovo

\begin{abstract}
RESUMO: A manutenção das áreas verdes urbanas sempre foi justificada pelo seu potencial em proporcionar qualidade de vida para a população. Essas áreas interferem diretamente na qualidade de vida por meio das funções ecológico-ambiental, estética, paisagística, psicológica e também recreativa para a população citadina. Tendo em vista a importância das áreas verdes urbanas, a presente pesquisa tem por objetivo caracterizar e analisar as principais praças da cidade de Mamborê, destacando os seus aspectos relacionados à vegetação, a fim de compreender a qualidade ambiental desses espaços públicos. A pesquisa foi dividida em etapas: analítica teórica, caracterizada pelo levantamento bibliográfico; levantamento fotográfico e vistoria in loco, para identificar e avaliar a harmonia entre praça (calçamento e iluminação) e aspecto da vegetação. Para tanto, utilizou-se da metodologia adaptada de De Angelis (2000) e Teixeira (1991). Os dados levantados na pesquisa indicam que as praças apresentaram condições satisfatórias no que diz respeito à harmonia entre vegetação, iluminação e calçamento. Todavia, foram identificadas algumas deficiências quanto ao planejamento desses espaços públicos por parte do poder público municipal. Mesmo sendo considerados espaços com boa presença de verde, estas praças não são amplamente frequentadas pelos moradores. Isso pode estar relacionado à carência em infraestrutura e a preferência por outros espaços mais atrativos, e não necessariamente à ausência de verde. Constatou-se que o poder público precisa mudar o posicionamento quanto às políticas implementadas para as praças da cidade.
\end{abstract}

Palavras-chave: Praças, áreas verdes, planejamento urbano.

\footnotetext{
${ }^{1}$ Bacharel em geografia, UNESPAR-Câmpus de Campo Mourão. E-mail.anacbfernades@gmail.com ${ }^{2}$ Bacharel em Geografia, Mestre em Engenharia Urbana-UEM. E-mail.silgaldino@outlook.com ${ }^{3}$ Doutor em Geografia. Professor Adjunto do Colegiado de Geografia e do Programa de PósGraduação Interdisciplinar Sociedade e Desenvolvimento da UNESPAR- Campus de Campo Mourão. E-mail.mcbovo@yahoo.com
} 


\title{
PUBLIC SQUARES IN MAMBORÊ-PR AS URBAN GREEN AREAS
}

\begin{abstract}
The maintenance of urban green areas was always justified by their potential to provide quality of life for the population. These areas interfere directly in quality of life through several functions for the urban population: ecological-environmental, aesthetic, landscape, psychological, and recreational as well. In view of the importance of such urban green areas, this research aims at characterizing and analyzing the main squares of Mamborê, highlighting their aspects related to vegetation, aiming at comprehending the environmental quality of such public spaces. The research was divided into some steps: an analytical theoretical one, characterized by bibliographic review; and a photographic survey and inspection in loco, to identify and evaluate the harmony between square (paving and lighting) and vegetation aspects. To do that, we used a methodology adapted from De Angelis (2000) and Teixeira (1991). Data acquired with the research indicate that the squares present satisfactory conditions regarding the harmony between vegetation, lighting and paving. However, some deficiencies were identified, concerning the planning of these public spaces by municipal public power. Even being considered as spaces with a good presence of green, such squares are not widely visited by citizens. That may be related to a lack in infrastructure and the preference for more attractive spaces, and not necessarily to the absence of green. We noted that public power needs a change of behavior regarding the implemented policies for the city's squares.
\end{abstract}

Keywords: Squares, green areas, urban planning.

\section{LAS PLAZAS DE MAMBORÊ-PR COMO AREAS VERDES URBANAS}

La manutención de areas verdes urbanas siempre fue justificada por su potencial en proporcionar calidad de vida para la población. Estas areas interfieren directamente en la calidad de vida a través de las funciones ecológico ambiental, estética, paisajística, psicológica y también recreativa para la gente citadina. Considerando la importancia de las areas verdes urbanas esta investigación tiene como objetivo caracterizar y analizar las principales plazas de la ciudad de Mamborê, destacando sus aspectos relacionados a la vegetación, al cabo de comprender la calidad ambiental de estos espacios públicos. La investigación fue dividida en varias etapas: analítica teórica, caracterizada por el inventario bibliográfico, inventario fotográfico e inspección in loco para identificar y evaluar la armonía entre plaza( empedrado e iluminación) y aspecto de vegetación. Para esto, se utilizó la metodología adaptada de De Angelis (2000) y Teixeira (1991). Los datos planteados en la investigación indican que las plazas presentan condiciones satisfactorias al que se refiere a la armonía entre la vegetación, iluminación y el empedrado. Aunque, fueron identificadas algunas deficiencias en relación al planeamiento de eses espacios públicos por parte del poder público municipal. Mismo siendo considerados espacios con buena vegetación verde, estas plazas no son utilizadas por los moradores con frecuencia. Esto estaría relacionado a la necesidad en la infra estructura y la preferencia por otros espacios más atractivos, y no necesariamente a la falta de vegetación verde. Se constató que, el poder público cambiar el posicionamiento en relación a las políticas implementadas para las plazas de la ciudad. 
Palabras clave: Plaza, Areas verdes, planeamiento público

\section{INTRODUÇÃO}

As praças constituem unidades urbanísticas essenciais para a vida urbana. Nas cidades ocidentais, elas são imprescindíveis, em face do papel que desempenham na vida social das diversas sociedades nas quais se inserem. $O$ modo como são tratadas e o uso que lhes é dado pela população indicam claramente o nível de criatividade de uma determinada cidade, bem como o exercício dos direitos e deveres de cidadania.

Dentre as funções, historicamente, elas eram um espaço cívico destinado à realização de discursos e espetáculos, à contemplação, ao encontro de pessoas e ao lazer, e nelas se colocava estátuas e monumentos. Porém, nos dias atuais, vários pesquisadores as denominam como área verde urbana, tendo em vista as funções ambientais e sociais que desempenham.

Dessa forma, faz-se necessário entender que as áreas verdes urbanas são conceituadas por Lima et al (1994) como espaços livres de construção, onde o elemento fundamental de composição é a vegetação, que, juntamente com o solo permeável, deve ocupar, no mínimo, $70 \%$ da área. Incluem as praças, os jardins públicos, parques urbanos, e também os canteiros centrais de avenidas, trevos e rotatórias permeáveis das vias públicas, e áreas que exercem funções estéticas e ecológicas. Lima et al (1994) também destacam que a praça é um espaço livre e público, cuja principal função é o lazer. Além disso, pode não ser uma área verde, quando não tem vegetação e encontra-se impermeabilizada.

De acordo com Nucci (1996), e Andrade e Bovo (2011), essas áreas verdes contribuem por: proteger a qualidade da água, impedindo que substâncias poluentes escoem para os rios; diminuir a quantidade de dióxido de carbono ( $\mathrm{CO} 2)$, através do processo de fotossíntese; aumentar a umidade relativa do ar, pela transpiração das folhas das árvores; diminuir a quantidade de resíduos sólidos no ar (por exemplo, a poeira); propiciar uma interação entre o homem e a natureza; contribuir para a 
estabilização climática, ao absorver parte da irradiação do sol, amenizando a temperatura e evitando a formação de ilhas de calor.

Em segunda instância, esses aspectos destacados por Nucci (1996), e Andrade e Bovo (2011), também contribuem para quebrar a monotonia das atividades humanas, influenciando tanto na melhoria das relações sociais, ou seja, na convivência entre as pessoas, como também na absorção das águas pluviais pelo solo, evitando assim problemas como enchentes, pois solos impermeabilizados não absorvem as águas pluviais.

Para Martins Júnior (1996, p. 7), "a área verde tem função de se constituir em um espaço 'social e coletivo', sendo importante para a manutenção da qualidade de vida". Por facilitar o acesso de todos, independentemente da classe social, promove integração entre os homens e a natureza. No entanto, a praça é vista por uma significativa parcela da população apenas como um lugar de recreação para as crianças ou de descanso para idosos.

Segundo Barros e Virgílio (2003), para que a praça de fato exerça todas as funções relacionadas acima, é necessário que a mesma esteja provida de elementos naturais e antrópicos, e que sua distribuição espacial seja democrática e atenda a totalidade da população.

Por essas razões, é de extrema importância que o planejamento urbano se preocupe em destinar áreas para praças, igualitariamente em todo o perímetro urbano, democratizando os benefícios proporcionados por elas. Para tanto, faz-se necessário que se compreenda a importância desse espaço e que ele seja incorporado nos planos urbanísticos, considerando que o planejamento, em sua essência, deve almejar uma infraestrutura urbana de qualidade.

Devido a essa importância, Andrade (2012, p. 12) destaca que "as áreas verdes como praças merecem ampla atenção das autoridades públicas que gerenciam a cidade porque toda e qualquer vegetação proporciona bem estar à população, seja em sentido de purificação do ar até sombreamento das árvores".

Em síntese, podemos destacar que a arborização age simultaneamente sobre os aspectos físico e mental do homem. No plano físico, ela absorve os ruídos e atenua o calor do solo; no plano psicológico, atenua o sentimento de opressão do 


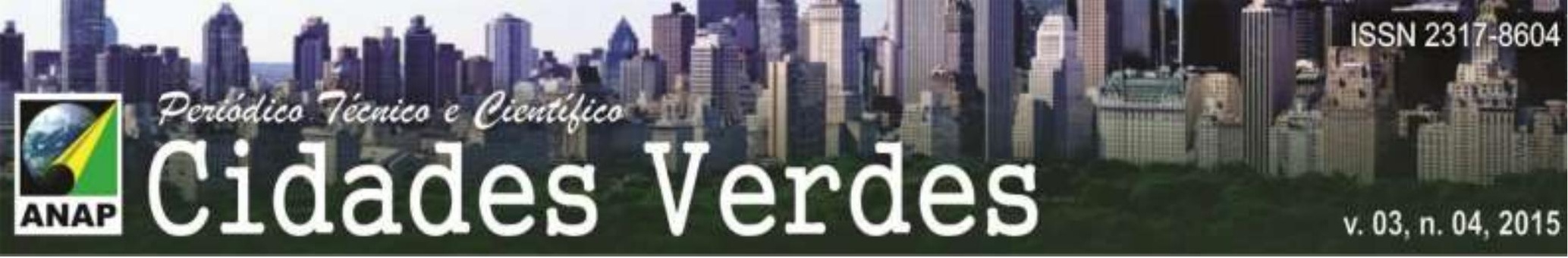

homem em relação às grandes edificações. Além disso, constitui-se em eficaz filtro das partículas sólidas em suspensão no ar, e contribui para a formação e o aprimoramento do senso estético, entre outros benefícios, conforme afirma Bovo (2009).

Tendo em vista a importância das áreas verdes urbanas, a presente pesquisa tem por objetivo caracterizar e analisar as principais praças da cidade de Mamborê, destacando aspectos relacionados à vegetação, a fim de compreender a qualidade ambiental desses espaços públicos.

\section{METODOLOGIA}

\subsection{Localização e características gerais da cidade de Mamborê (PR)}

Esta pesquisa foi realizada no município de Mamborê, localizado na Mesorregião Centro Ocidental Paranaense (IPARDES, 2011). O município faz parte da Microrregião Homogênea 286 e pertence à COMCAM - Comunidade dos Municípios da Região de Campo Mourão, limitando-se com Campo Mourão e Farol ao Norte, com Boa Esperança e Juranda a Oeste, com Campina da Lagoa e Nova Cantu ao Sul, e com Luiziana a Leste (Figura 1).

Figura 1: Município de Mamborê/PR, com destaque para o perímetro urbano.

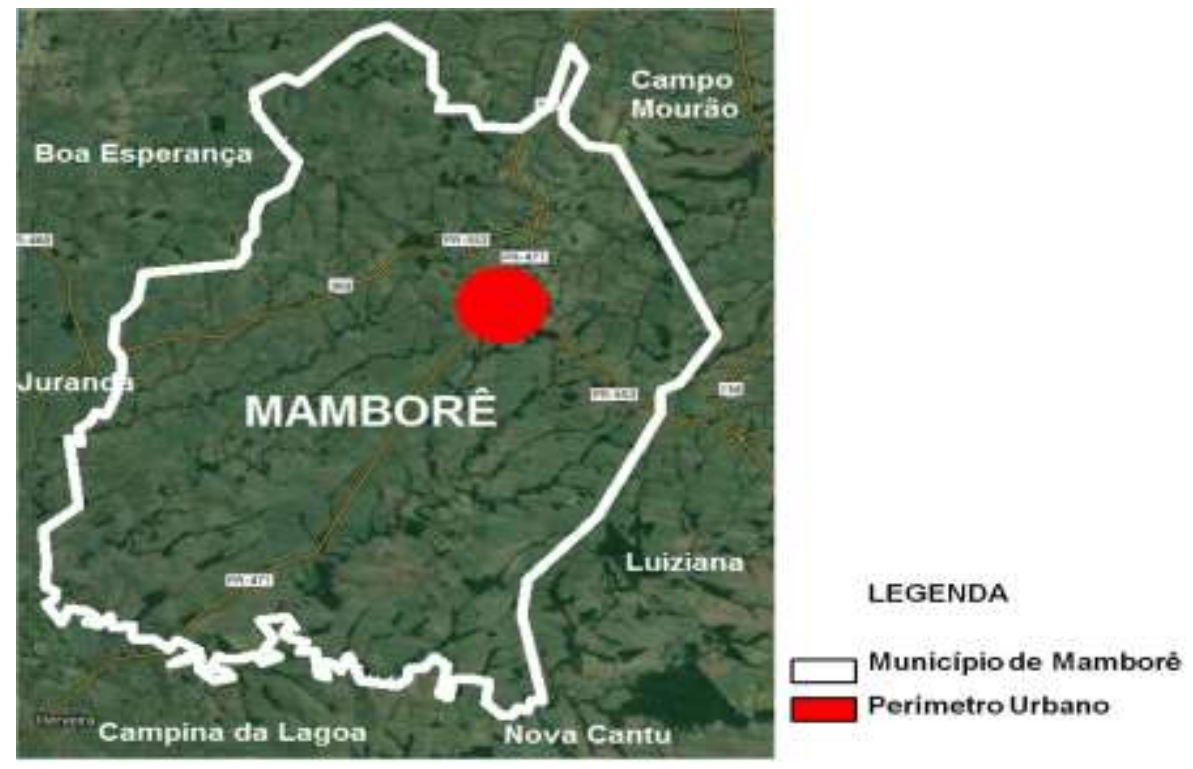

Fonte: Adaptado de GOOGLE, 2014. 
O município de Mamborê ocupa aproximadamente $788,062 \mathrm{~km}^{2}$ de área no terceiro planalto paranaense, entre as coordenadas de "24¹7'30" de latitude Sul e " $52^{\circ} 31^{\prime} 10^{\prime}$ " de longitude Oeste, com $980 \mathrm{~m}$ de altitude. O clima do município é do tipo Cfa ou Subtropical Úmido, sendo a média pluviométrica anual de $1.500 \mathrm{~mm}$, e a média de temperatura de $20^{\circ} \mathrm{C}$. Possui uma população de 13.961 habitantes; destes, 8.984 residem na área urbana, de acordo com o Instituto Brasileiro de Geografia e Estatística (IBGE, 2010).

\subsection{Procedimentos metodológicos}

Para a realização da pesquisa, primeiramente foram selecionadas quatro praças localizadas no perímetro urbano da cidade de Mamborê, em cujo entorno predominam atividades residenciais, comerciais e serviços. As praças selecionadas são: Praça das Flores, Praça Marechal Candido Mariano da Silva Rondon, Praça Prefeito João Szesz e Praça Alvorada (Figura 2).

Figura 2: Localização da área de estudo.

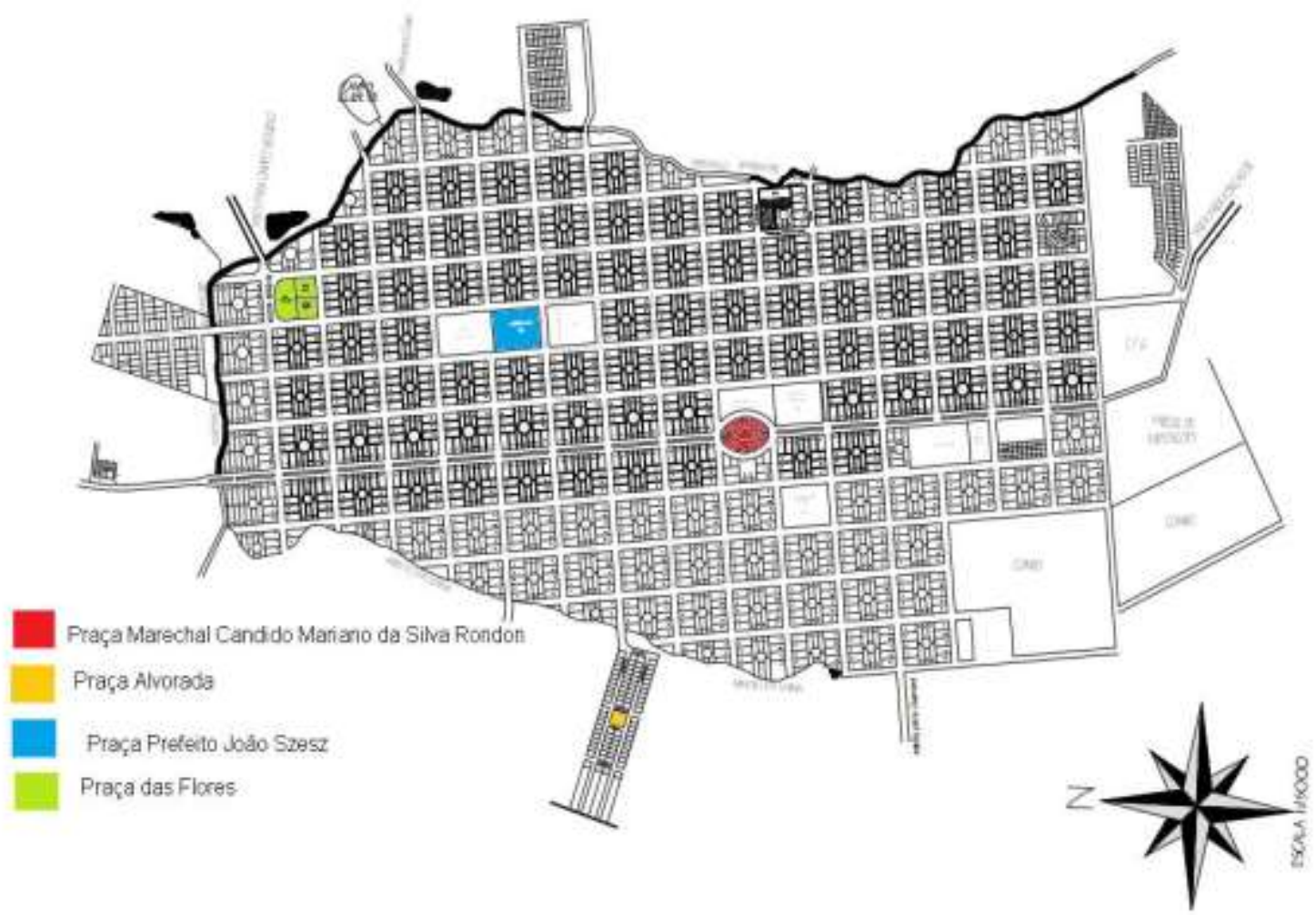

Fonte: Prefeitura Municipal de Mamborê, adaptado por AYRES, A. C. B. F, 2014. 
Os procedimentos metodológicos adotados foram os seguintes: pesquisa bibliográfica, levantamento de campo e análise dos resultados. Dessa forma, foram realizados estudos bibliográficos de teses, dissertações, livros, artigos, periódicos e jornais relacionados às áreas verdes urbanas, com o objetivo de respaldar a fundamentação teórica para a sustentação e elaboração do estudo.

Realizarmos visitas in loco com o objetivo de levantar e avaliar a vegetação existente nessas praças. Dessa forma, para o estudo das principais características básicas e ambientais das praças, utilizou-se parcialmente da metodologia desenvolvida por Teixeira (1991) e De Angelis (2000), adaptada segundo a realidade dessas praças públicas.

Quanto aos aspectos físico-sanitários da vegetação, foram utilizados os seguintes parâmetros adotados por Teixeira (1991):

- Bom: refere-se à vegetação que está isenta de sinais de praga e doenças ou injúrias mecânicas;

- Satisfatório: para vegetações que apresentam pequenos problemas de pragas, doenças e danos físicos, necessitando de poda;

- Ruim: quando se verifica severos problemas desencadeados por pragas, doenças ou danos físicos;

- Morta ou com morte aparente.

Para diferenciar a qualidade paisagística, utilizamos os seguintes parâmetros:

- Bom: quando se apresentam sem danos, em condições de uso pleno;

- Satisfatório: quando se apresentam com pequenos danos, possibilitando o uso.

- Ruim: quando se apresentam com danos que impossibilitam o uso pleno.

\section{ANÁLISES DOS RESULTADOS}

Neste item, apresentamos as análises gerais realizadas nas quatro praças pesquisadas na cidade de Mamborê, destacando as características gerais dessas áreas verdes e, em específico, da vegetação e de sua qualidade ambiental. 


\subsection{Praça Marechal Candido Mariano da Silva Rondon}

A Praça Marechal Candido Mariano da Silva Rondon encontra-se localizada entre a Avenida Paulino Ferreira Messias e as ruas Vereador Sidney Barth e Itacil Martins. A praça possui uma forma circular, e é mais conhecida como a "Praça da Rodoviária”, por estar localizada em frente ao Terminal Rodoviário de Mamborê.

Embora se situe na região central da cidade, seu entorno é misto, ou seja, é constituída por residências e comércios. Mediante as observações in loco, constatou-se que a praça não apresenta área de pavimentação danificada por raízes de árvores, realidade muito comum nesses logradouros públicos.

A praça apresenta uma situação satisfatória no que se refere à relação vegetação-pavimentação, devido à "harmonia" suficiente entre os espaços de calçamento e espaços do "verde". Dessa forma, o "verde", na cidade, mais do que uma ornamentação, tem que ser "adaptado", sendo necessárias constantes intervenções para que este se mantenha praticamente "estático" em seu tamanho e distribuição, de modo que ocupe somente seu espaço específico no conjunto da obra.

Outro ponto a considerar nesta praça se refere à condição vegetaçãoiluminação, uma vez que as copas das árvores não impedem a iluminação, sendo esta considerada como satisfatória. Mesmo as árvores presentes sendo de porte arbóreo, o logradouro apresenta iluminação do tipo baixa, impedindo que a luz seja bloqueada tanto pelos galhos como pelas folhas das árvores, garantido a ampla funcionalidade logradouro.

Quanto à caracterização da vegetação existente na praça, foram identificadas espécies arbóreas frutíferas e árvores nativas (Figura $3 \mathrm{~A}$ e B). A presença de espécies frutíferas foi considerada como fator negativo, pois a prioridade deve ser por árvores que garantam sombreamento, e não que produzam frutos, para facilitar a limpeza e manutenção da praça. 


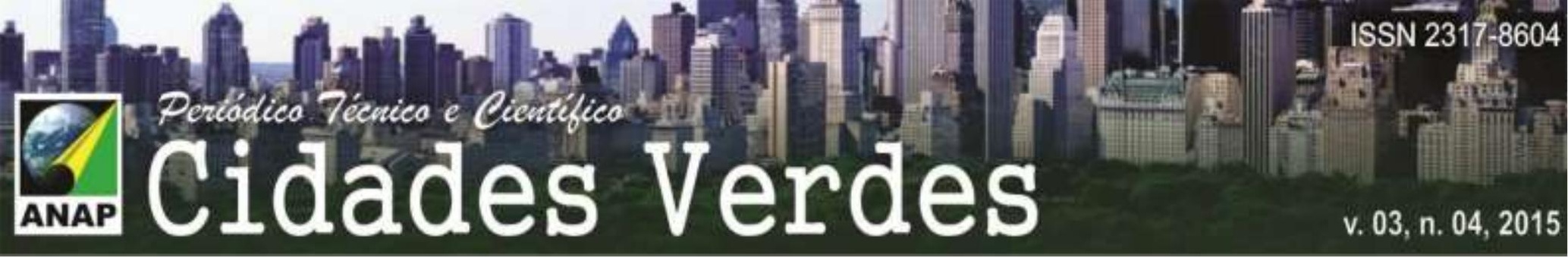

A praça em questão passou por um processo de revitalização nos últimos anos, e encontra-se em bom estado, cumprindo de maneira satisfatória a função social enquanto equipamento urbano.

Mediante as observações in loco, evidenciou-se que a praça não apresenta áreas de pavimentação danificadas por raízes de árvores, e apresenta uma situação satisfatória no que se refere à relação vegetação-pavimentação, pois existe uma "harmonia" suficiente entre os espaços de calçamento (pavimentação ou piso) e espaços do "verde" (canteiros).

Outro fator levado em consideração refere-se à relação vegetaçãoiluminação. Nessa praça, a relação é satisfatória, pois a iluminação principal é do tipo baixa. Dessa forma, a copa das árvores não impede que a luz se distribua ou se disperse pela praça. Quanto à caracterização da vegetação existente na Praça Alvorada, foram identificadas espécies arbóreas infrutíferas e algumas frutíferas, dentre as quais estão: Ligustro (Ligustrumlucidum W. T. Aiton), Jerivá (Syagrusromanzoffiana), e Pata-de-Vaca (Bauhiniaforficata) (Figuras 4 A, B e C).

Figura 4: Espécies arbóreas presentes na Praça Alvorada: A - Ligustro (Ligustrumlucidum W. T. Aiton); B Jerivá (Syagrusromanzoffiana); C - Pata-de-Vaca (Bauhiniaforficata).

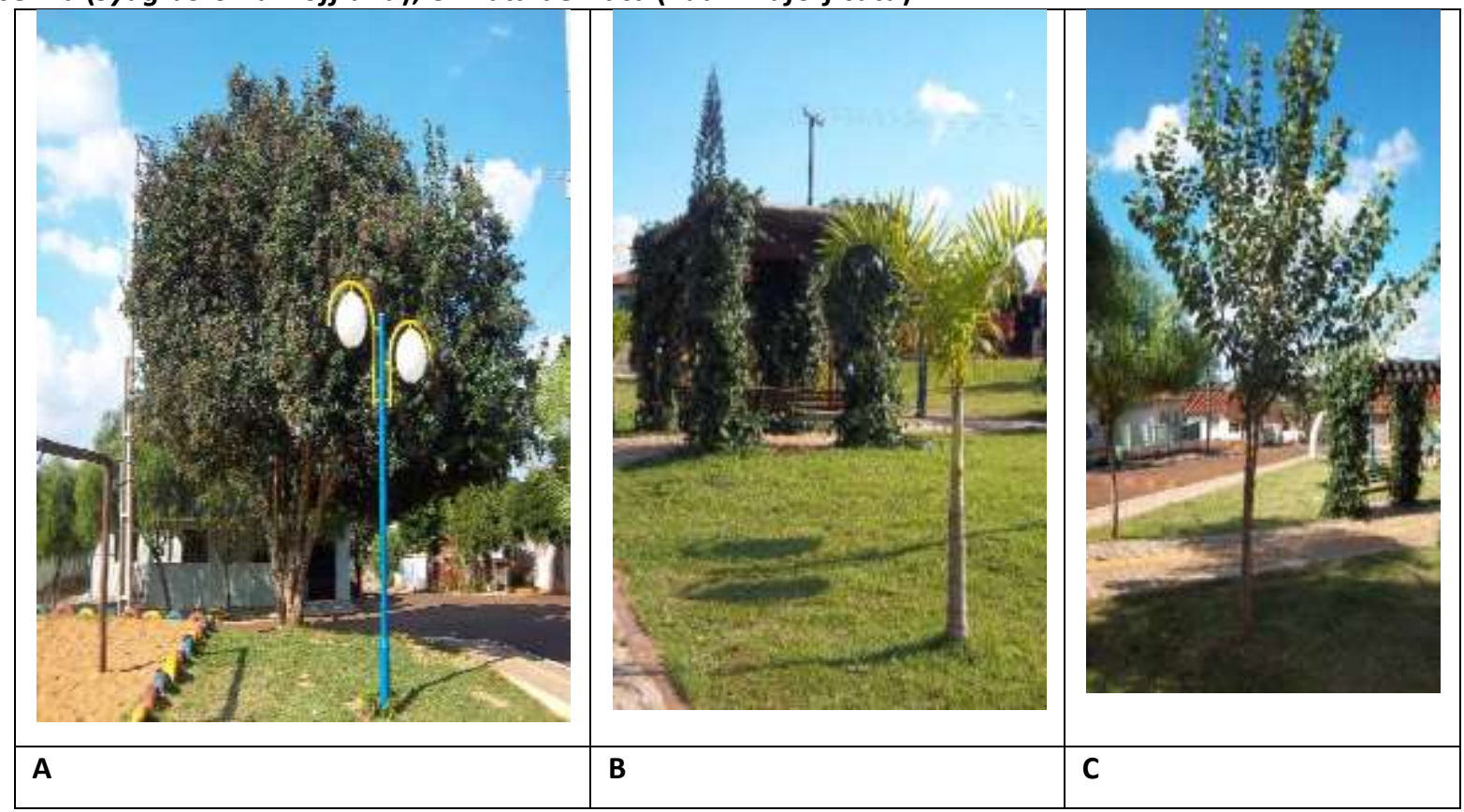

Foto: Acervo pessoal, 2014. 
De modo geral, a vegetação da Praça Alvorada encontra-se em bom estado, com espécies de porte pequeno. Todavia, os gramados não apresentam manutenção e zelo por parte do poder público local que administra a praça. Por outro lado, os canteiros não se encontram danificados e a própria vegetação não "invadiu" a área de calçamento do espaço público.

Com base nos parâmetros de avaliação de Teixeira (1991), a vegetação da Praça Alvorada se enquadra na categoria "satisfatória", ou seja, a vegetação apresenta bons aspectos físicos sanitários, porém são insuficientes para a praça.

No que se refere à qualidade paisagística, ainda segundo os parâmetros de Teixeira (1991), a praça em questão enquadra-se novamente na categoria "satisfatória", ou seja, a praça não apresenta danos que impeçam ou dificultem o seu usufruto pela população. Isso advém da boa atuação do poder público no logradouro, que tem cumprido seu caráter de socialização e interação entre as pessoas.

\subsection{Praça Prefeito João Szesz}

A Praça Prefeito João Szesz é popularmente conhecida como "Praça da Matriz", por localizar-se em frente à Igreja Matriz, na Avenida Augusto Mendes dos Santos e Avenida Manuel Francisco da Silva com a Rua Piraí e Rua Guadalajara, no centro de Mamborê, em seu possui comércios.

Mediante as observações in loco realizadas, constatou-se que a praça não apresenta áreas de pavimentação danificada por raízes de árvores. Sua condição é satisfatória no que se refere à relação vegetação-pavimentação, pois se observa uma "harmonia" suficiente entre os espaços de calçamento e espaços do "verde".

Quanto à condição da vegetação-iluminação é boa, uma vez que as copas das árvores não impedem a iluminação da praça. As árvores presentes são de porte arbóreo, porém não bloqueiam a iluminação por serem baixas.

Nessa praça, identificamos várias espécies arbóreas, com predomínio da Sibipiruna (Caesalpinia pluviosa sin), Ipê-Amarelo (Tabebuia alba), Flamboyant (Delonixregia Sandwith), entre outras. As espécies de árvores nativas 


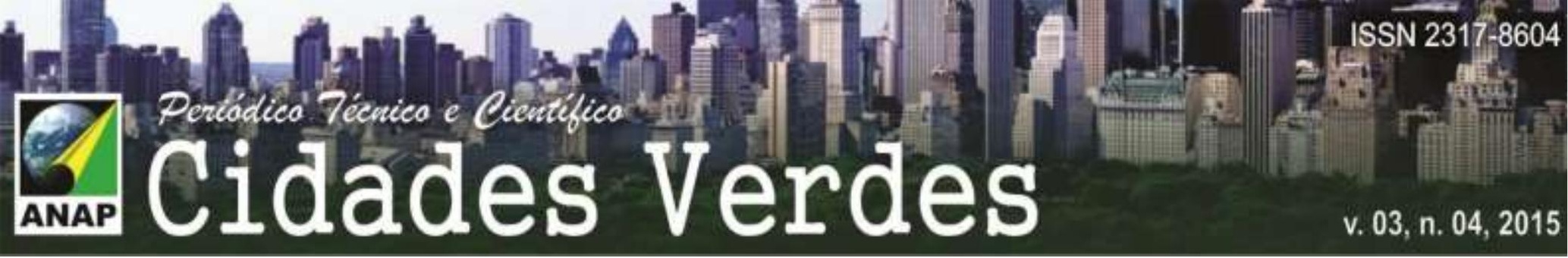

também constituem um ponto positivo desse espaço público, tendo em vista a preservação de tais espécies.

Além de espécies arbóreas, também há a existência de "espécies de forração", de caráter especialmente estético, mas que, em conjunto, caracteriza a agradabilidade ambiental do espaço (Figura 5). Em muitas das árvores, evidenciouse a presença da Costela-de-adão ou banana-de-macaco (Monstera deliciosa). Esta possui uma folhagem exótica e exuberante, que adere bem ao caule das árvores.

Figura 5: Espécies arbóreas na Praça Prefeito João Szesz

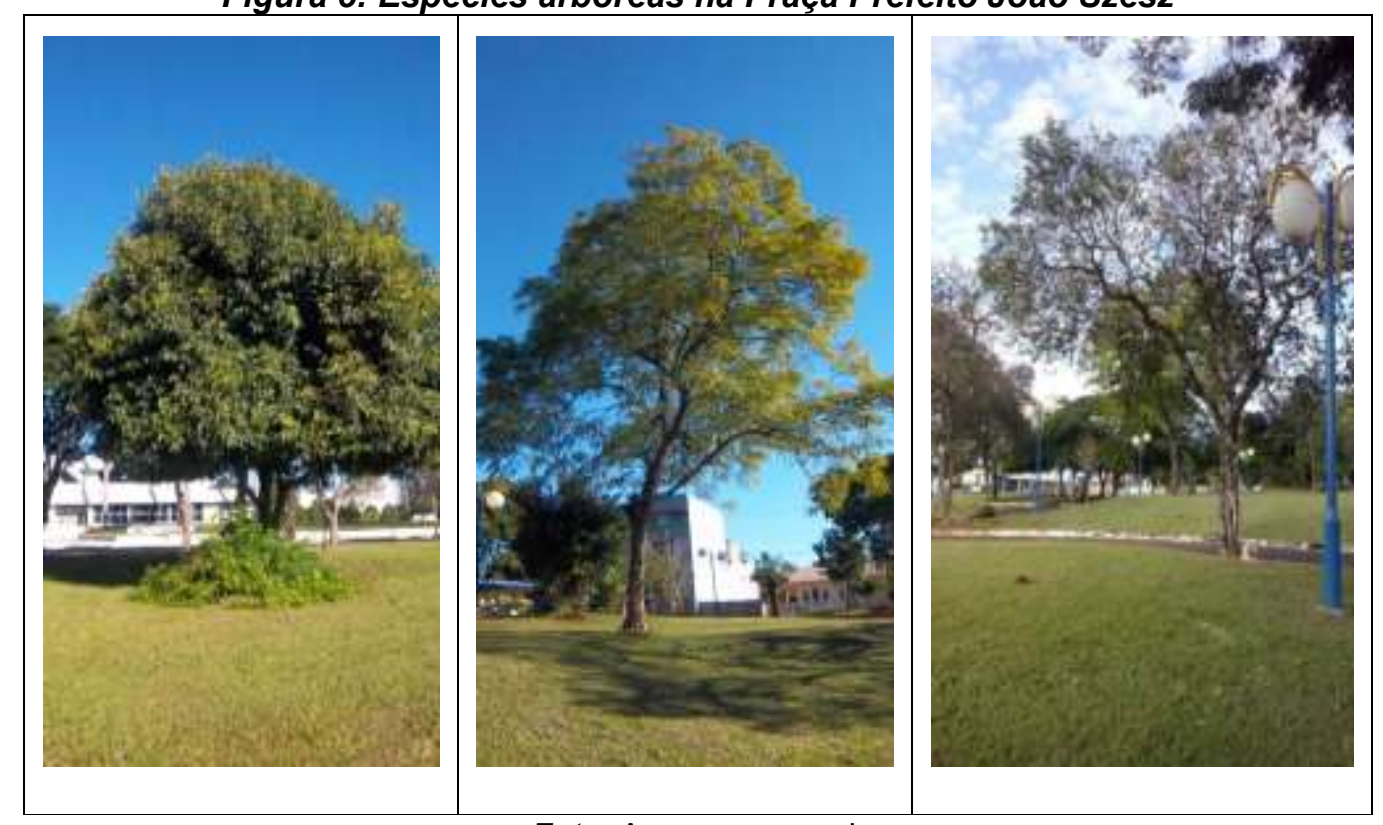

Foto: Acervo pessoal.

De acordo com os parâmetros de avaliação de Teixeira (1991), a vegetação presente na praça se enquadra na categoria "boa", ou seja, encontra-se praticamente isenta de pragas e doenças. Sendo lugar de grande fluxo de pessoas diariamente, a área central do município (que inclui o espaço da Praça Prefeito João Szesz) é palco privilegiado para que o poder público faça mostre suas realizações.

Quanto à qualidade paisagística, ainda segundo os parâmetros de Teixeira (1991), a praça em questão enquadra-se novamente na categoria "bom", ou seja, não apresenta danos significativos e está em condições de uso pleno, novamente confirmando a situação de boa conservação. 


\subsection{Praça das Flores}

A Praça das Flores está localizada entre a Avenida Augusto Mendes dos Santos e as ruas Abel Desidério de Araújo e Ricardo Kauffamann. A praça possui forma quadrangular, e também se localiza na área central da cidade de Mamborê, com número considerável de comércios ao entorno. Mesmo com localização em área central, a praça apresenta vários problemas quanto aos serviços de manutenção, deixando de cumprir de maneira satisfatória sua função social enquanto equipamento urbano. Mediante as observações in loco, contatou-se que a praça apresenta áreas de pavimentação danificada por raízes de árvores. Tal situação dificulta o uso da praça pela população, especialmente portadores de necessidades especiais.

A praça não apresenta uma situação satisfatória no que se refere à relação vegetação-pavimentação, pois não há "harmonia" suficiente entre os espaços de calçamento (pavimentação ou piso) e espaços do "verde". Outro fator refere-se à relação vegetação-iluminação: nessa praça, tal relação é boa, pois sua iluminação principal é do tipo baixa. Dessa forma, as copas das árvores não impedem que a luz se distribua ou se disperse.

Quanto à caracterização da vegetação existente na Praça das Flores, identificamos somente espécies arbóreas infrutíferas. Além de espécies arbóreas, a praça ainda abriga formações arbustivas e certas "espécies de forração" (Figura 6). 


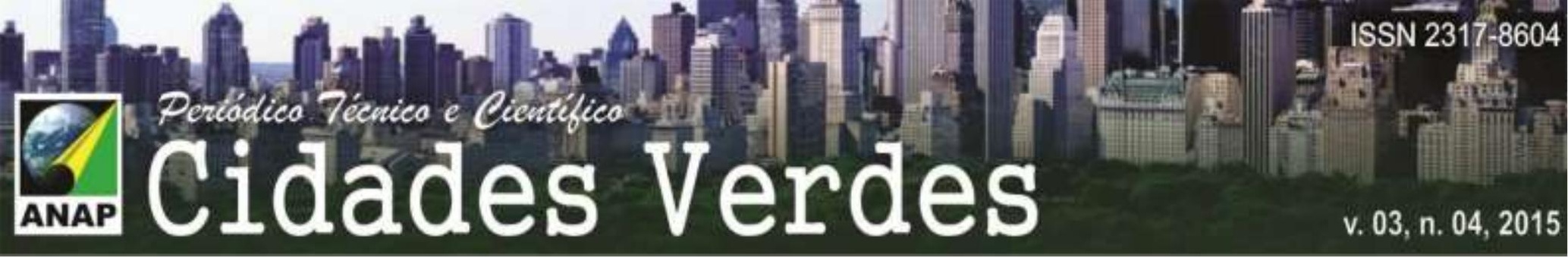

Figura 6: A - Espécies arbóreas evidenciadas na Praça das Flores; B - Espécies arbustivas na Praça das Flores; C - Espécies de forração na Praça das Flores

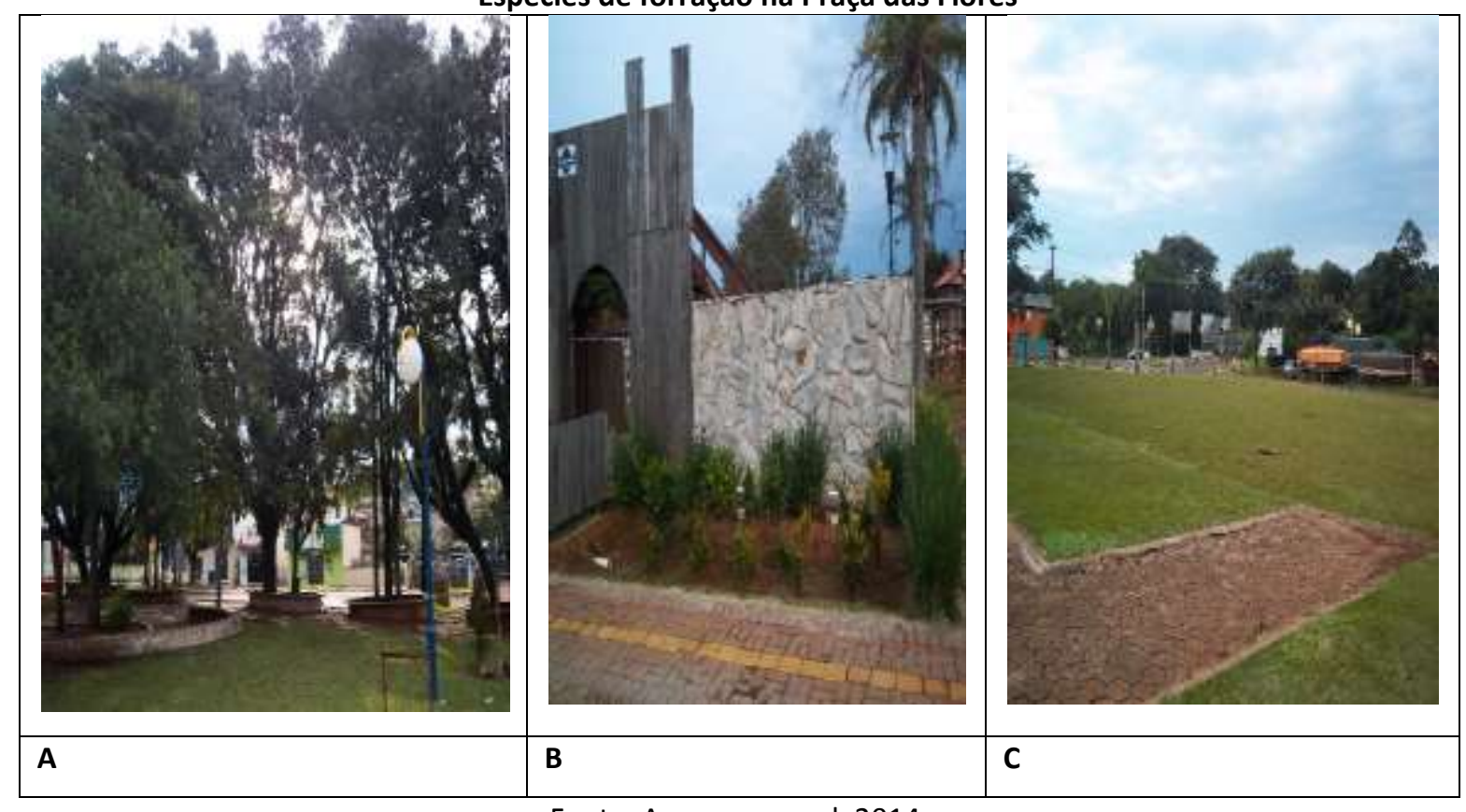

Fonte: Acervo pessoal, 2014.

A vegetação da Praça das Flores encontra-se em estado ruim, pois os serviços de poda e manutenção não são realizados com frequência. Os gramados dos canteiros também não passam por manutenção ou zelo por parte do poder público local, que administra a praça. Em vários pontos, os canteiros estão danificados, e os gramados e raízes das árvores "invadiram" a área de calçamento do espaço público, inviabilizando ou dificultando um simples passeio pela praça.

Com base os parâmetros de avaliação de Teixeira (1991), a vegetação presente nessa praça se enquadra na categoria "ruim", ou seja, apresenta severos danos físicos, necessitando de poda urgente e de maiores cuidados, bem como a substituição de árvores antigas por espécies novas.

Entretanto, no caso de Mamborê, percebe-se uma realidade bem diferente, pois a Praça das Flores está localizada na entrada principal da cidade e, mesmo assim, o poder público deixa a desejar em relação aos aspectos mobiliários e vegetação.

Em sentido de qualidade paisagística, ainda segundo os parâmetros de Teixeira (1991), a praça em questão enquadra-se novamente na categoria "ruim", ou seja, apresenta sérios danos que impedem ou dificultam o usufruto pela população. 
Isso advém da falta de atuação do poder público em tal logradouro, o qual necessita de revitalização urgente para cumprir novamente seu caráter histórico de socialização e interação entre as pessoas.

\section{CONSIDERAÇÕES FINAIS}

As áreas verdes desempenham papel importante no mosaico urbano, pois constituem um espaço encravado no sistema urbano cujas condições ecológicas em muito se aproximam com a natureza. Diante disso, contatou-se que o poder público precisa urgentemente mudar o posicionamento quanto às políticas implementadas para as praças da cidade de Mamborê, visando à requalificação dessas áreas, para atender as necessidades da comunidade.

Diante da problemática existente relacionada às áreas verdes urbanas, propomos as seguintes sugestões, visando à melhoria não só das praças, mas também de outras áreas existentes na cidade: a) criar medidas e diretrizes políticas para o aproveitamento das potencialidades das áreas verdes mamboroeenses, seja para lazer, seja para fins estéticos ou ecológico-ambientais, visando à qualidade de vida da população citadina; b) propor medidas para a melhoria dos aspectos físicos e sanitários da vegetação, levando em consideração: as espécies introduzidas em cada espaço público; a mão de obra treinada e especializada; o plantio e acompanhamento do crescimento, poda e tratamento, obedecendo às técnicas adequadas; c) criar políticas públicas visando à implantação e à recuperação das estruturas e dos equipamentos mobiliários a serem implantados em cada área verde, levando-se em consideração as funções básicas dessas áreas, que são a socialização e o lazer, sejam estes de caráter cultural, recreativo, esportivo ou contemplativo; d) desenvolver políticas públicas de conscientização da população sobre a importância das áreas verdes urbanas, estimulando o uso desses espaços livres a fim de promover a qualidade de vida da população.

Dessa forma, entendemos que a preocupação com a preservação do verde nos espaços públicos deve ser uma constante para todos os cidadãos, poder público e profissionais que atuam na área. 


\section{REFERÊNCIAS}

ANDRADE, T. B; BOVO, M. Aspectos relacionados ao uso e apropriação de espaços públicos urbanos: o caso das praças centrais de Campo Mourão - PR. Anais I SEURB - I Simpósio de Estudos Urbanos: Desenvolvimento Regional e Dinâmica Ambiental. Faculdade Estadual de Ciências e Letras de Campo Mourão. 2011.

ANDRADE, T, B. Praças, poder público e população: uma (re) leitura da imagem e uso das praças centrais de Campo Mourão - PR. Monografia de Geografia (Especialização) apresentada na Faculdade Estadual de Ciências e Letras de Campo Mourão. Campo Mourão. 2012.

BARROS, M.V.F; VIRGÍLIO. H. Praças: espaços verdes na cidade de Londrina. Revista do Departamento de Geociências. Volume 12, n. ${ }^{\circ}$ 1, Londrina, 2003. pp.533-544.

BOVO, M. C. Áreas verdes urbanas, imagem e uso: um estudo geográfico sobre a cidade de Maringá-PR. Tese de (Doutorado em Geografia) Universidade Estadual Paulista, Faculdade de Ciências e Tecnologia. Presidente Prudente, 2009.

DE ANGELIS, Bruno Luís Domingos. A Praça no Contexto das Cidades: o caso de Maringá-PR. Tese de (Doutorado em Geografia). Faculdade de Filosofia, Letras e Ciências Humanas Universidade de São Paulo. São Paulo, 2000.

IBGE - cidades. Mamborê. Disponível em: <http://www.ibge.gov.br/cidadesat> acesso em: 20 de março de 2015.

IPARDES. Caderno estatístico município de Mamborê-PR. Dezembro de 2014. Disponível em: $<$ http://www.ipardes.gov.br/cadernos/Montapdf.php?Municipio=87340> acesso em: 26, de Fevereiro de 2015.

LIMA, A. M. L. P.et al. Problemas na utilização na conceituação de termos como espaços livres, áreas verdes e correlatos. Anais. Congresso Brasileiro de Arborização Urbana, 2. São Luís. Anais... São Luís: Imprensa Emater/MA, 1994.

MARTINS JUNIOR, O.P. Uma cidade ecologicamente correta. Goiânia: A B Editora, 1996.

$\mathrm{NUCCI}$, João Carlos. Qualidade ambiental e adensamento urbano: um estudo da ecologia e do planejamento urbano aplicado ao Distrito de Santa Cecília (MSP), Tese (Doutorado em Geografia Física)-Faculdade de Filosofia, Letras e Ciências Humanas, Universidade de São Paulo, 1996.

TEIXEIRA, I. F. SANTOS, N. R. Caracterização das áreas verdes do perímetro urbano de Santa Catarina- RS. Anais- Encontro Nacional de Estudos sobre o Meio Ambiente, e, 1991, Londrina. Anais... Londrina, 1991. 